\title{
Social Perceptions, Behaviors and Therapeutic Routes Related to High Blood Pressure in Women from Banco to Bouake
}

\author{
Siméon Meless Akmel*, Hilaire Gnazégbo Mazou, Patrice Edmond Yao Kouakou \\ Department of Anthropology and Sociology, University Alassane Ouattara-Bouake, Ivory Coast \\ Email address: \\ melessovsky65@gmail.com (S. M. Akmel), hilairemazou@yahoo.fr (H. G. Mazou), peyk.jubile@yahoo.fr (P. E. Y. Kouakou) \\ ${ }^{*}$ Corresponding author
}

\section{To cite this article:}

Siméon Meless Akmel, Hilaire Gnazégbo Mazou, Patrice Edmond Yao Kouakou. Social Perceptions, Behaviors and Therapeutic Routes Related to High Blood Pressure in Women from Banco to Bouake. World Journal of Public Health. Special Issue: Women, Health and Sustainable Development in Under Developed Country. Vol. 5, No. 3, 2020, pp. 47-52. doi: 10.11648/j.wjph.20200503.11

Received: April 7, 2020; Accepted: April 22, 2020; Published: July 6, 2020

\begin{abstract}
High blood pressure is a public health problem in sub-Saharan Africa, more particularly in Ivory Coast. It causes stroke, heart failure, kidney failure and coronary heart disease, the leading causes of death worldwide. This situation has led political authorities, researchers, NGOs to reflect on reality. The objective of this research is to analyze the social perceptions, behaviors and therapeutic routes linked to high blood pressure in the "Koyaka" populations from Banco to Bouake, field of investigation. We conducted research, both qualitative and quantitative, carried out using data collection tools (questionnaire, observation guide, consultation registers, interview guide) with 100 individuals. The work, which presents results from the field, analyzes the meaning that the Koyaka give to high blood pressure (causes, consequences). Then, it explains the behaviors (poor nutrition) and the response of the actors (therapeutic routes) in the face of the disease. Therefore, medical anthropology must be associated with the fight against this pathology.
\end{abstract}

Keywords: Social Perception, High Blood Pressure, Behavior, Therapeutic Itinerary, Medical Anthropology, Ivory Coast

\section{Introduction}

The issue of high blood pressure has aroused particular interest around the world. As a result, several studies are being carried out to describe the situation of this disease which is gaining more and more ground in the world. Formerly known as Western illness (white disease), high blood pressure (hypertension) also affects developing countries. Faced with this situation, political and administrative authorities, researchers tried to understand the disease and explain it, through different theoretical approaches, namely medical, economic or socioanthropological. According to Abdoul [1], more than 100 million people are hypertensive in Africa, of which 90 million are out of control, and $80 \%$ of recourse to traditional medicine.

As early as the 1970s, argues Jarraya [2], the first survey assessing the prevalence of hypertension in 8052 subjects living in the city of Tunis, and 4531 subjects living in the rural area of Siliana was carried out. The prevalence is $11.9 \%$ in Tunis, going from $1.8 \%$ for the population under 30 years old, to $32.6 \%$ for that of over 40 years old. The female prevalence of hypertension is $8.9 \%$, higher than that of men $(7.3 \%)$.

Boukare [3] discusses the determinants of hypertension in Ouagadougou. His study identified the advanced age, the semi-urban environment and the family history of the disease, the difference between the urban area and the urban area not urban as risk factors.

The situation of hypertension is not brilliant in Ivory Coast. Indeed, Bouaké, a city that lives to the rhythm of large cities, is not spared. The prevalence of high blood pressure has risen from $13.7 \%$ at the end of 1979 to more than $25 \%$ today, an established prevalence of 20 to $30 \%$. The Banco district interests the study for several reasons: The existence of social perceptions among the "Koyaka". They are physical and come from respondents with biomedical knowledge: "Hypertension is not a disease, but it causes pathologies, such 
as stroke, paralysis...". These perceptions are also sociocultural and justified by the illiterate, and people with primary education in these terms: "The disease is a spell cast by sorcerers, it is not simple". -The existence of risky behaviors linked to hypertension. They rhyme with their ways of dealing with illness. Despite the threat posed by high blood pressure, people are addicted to unsafe tobacco, alcohol and unhealthy eating. Different reactions to the disease. To recover their state of physical, mental and social well-being, the populations have recourse to various therapeutic procedures (modern, traditional care). From these findings arises the main question that follows: "How do the social perceptions of hypertension influence behavior and therapeutic routes among the Koyaka"? Related to this question are the secondary ones: "What are the social perceptions of high blood pressure among the Koyaka"? "How do they behave in the face of illness"? "What are the therapeutic practices related to high blood pressure among the Koyaka"?

The objective of this research is to analyze social perceptions, behaviors and therapeutic routes related to high blood pressure in Koyaka populations. From this objective flow three specific objectives, the first of which consists first of all, in identifying social perceptions; Then describe the behaviors of the actors; Finally, to analyze the reactions of populations facing the disease. The thesis defended is as follows: "Social perceptions of high blood pressure influence the behavior and therapeutic practices of the Koyaka". Attached to this thesis are hypotheses: "The social perceptions of hypertension are linked to the socio-cultural environment of the populations"; "Social perceptions influence the behavior of the Koyaka"; "Modern and traditional medicines represent the therapeutic practices of populations".

\section{Method}

\subsection{Investigation Site}

Our survey site is the Banco district, located in Bouake (center of Ivory Coast), a municipality which covers 71,788 $\mathrm{km}^{2}$, and populated according to the national statistics institute, of 1,542,000 inhabitants. Banco is located south of Bouaké. It is bounded to the north by N'Gattakro, to the east by Houphouët-Town, to the south by Broukro. The population concerned by the study is estimated at 300 people, according to the field survey. The choice of this site is linked to the poverty which prevails there, and the actual existence of people affected by high blood pressure; which makes the disease a public health problem.

\subsection{Data Collection Technique and Theories of Analysis}

The respondents are mainly Koyaka women from Banco, victims of the disease. Their age varies between 40 and 70 years (age group exposed to the disease). Also, teachers, health workers (Ahougnansou health center, N'Gattakro, $\mathrm{CHU})$, employees, resource people are chosen. They helped justify the extent of the disease in the area. To this was added the availability of respondents: only individuals wishing to answer the questions were retained, some having refused to lend themselves to the questions. The experience also helped to choose the respondents. With regard to the study, 300 people, victims of high blood pressure were identified (sampling frame). Unable to interview all of the individuals, we decided to retain 100 people. These are the women, who actually contracted the disease, who lent themselves to our questions (our sample, about a third (1/3) of the population). We made a reasoned choice, to target key people. Through two focus groups of five people each, ten women were interviewed. To give everyone a chance to be included in the study, we ran a random draw. A total of 100 people were chosen and interviewed. From the questionnaire and the registers, we quantified the information collected, relating to the opinions, behaviors and therapeutic routes of the actors. Using the MAXQDA software, the data is qualitatively processed. When the SPSS software allowed the quantitative processing of information. To deepen the analysis of the data, we mobilized Aline's theory of social representations [4], to grasp the ways of thinking and feeling relating to high blood pressure. Noppen's dialectical analysis [5] has made it possible to justify the ways of feeling linked to high blood pressure, the different behaviors and the therapeutic routes of the actors. The methodological approach made it possible to obtain the results.

\section{Result}

\subsection{Social Perceptions of High Blood Pressure}

\subsubsection{Knowledge of Hypertension}

Through the interview guide and the questionnaire, we present the information collected from resource people. To do this, we asked respondents: "Do you know about high blood pressure"? Here are some of the responses:

"High blood pressure is not a disease in itself. This is when your blood pressure rises above normal. This rise can cause health problems, which can lead to a heart attack, paralysis, etc. It is dangerous because of the harmful consequences. That is why it is important to take your blood pressure regularly and follow the prescriptions of the doctors. This is a real public health problem "(H. P, Teacher, 48 years old; P. B, Health worker, 51 years old).

"I don't know too much, but it looks like it's when the tension goes up. Often when the wizards are behind you, they pass by. I know a man, who was attacked by wizards in the village. Suddenly, he fell from a motorcycle in town, on his way home from work. Many people attributed this to tension. Yet he was mowed down by obscure hands from his village" (F. T, Housewife, 52 years old).

Through these words, two categories of actors emerge. The first has biomedical knowledge on high blood pressure. It defines it and shows the existence of certain provisions aimed at its prevention. The second category ignored the disease. The approximate perceptions are linked to the 
cosmogony, even the socio-cultural environment of the populations. The data in the following table rhymes with the above comment.

Table 1. Knowledge of High Blood Pressure.

\begin{tabular}{lll}
\hline Numbers Answers & Respondents & Pourcentage (\%) \\
\hline Good knowledge & 16 & 16 \\
Bad knowledge & 84 & 84 \\
Total & 100 & 100 \\
\hline
\end{tabular}

Source: Our survey, 2019.

Out of 100 people questioned, only 16 or $16 \%$ have a favorable opinion. This section of the population has a good knowledge of high blood pressure. It is made up of women respondents with a secondary or higher education level, but also health workers working in hospitals and dispensaries. Conversely, the second category, which represents the most important social category in number, around $84 \%$ have a poor knowledge of the disease. It is made up of illiterates and people who dropped out of school very early. Causes explain the disease.

\subsubsection{Factors Associated with High Blood Pressure}

To understand the causes of hypertension, we asked respondents the following question: "What causes the disease"? Here are some of the responses:

"For me, high blood pressure is caused by poor diet. Today, there are too many chemicals in everything we eat. Added to this is the stress linked to everyday problems (poverty, unemployment, illnesses). Anxiety is part of the daily lives of populations, which favors this situation. We should also not forget the lack of sport that affects our health. Alcohol is not to be outdone, because it negatively affects the health of people " (H. P, Health worker 50 years; B. T, Employee).

"I have always said that bad people are the people who cause high blood pressure. When a wizard is behind you, he goes to great lengths to do harm. But, those who do not know it, think it is a normal disease. I've had several experiences, and I know what I'm talking about. The fate related to this disease is common. Often missing persons who are not satisfied with certain living people act to restore order or justice." (D. F, Vendeuse, 53 years old; S. M, Housewife, 60 years old).

From this information, there are two causes linked to hypertension. The first is physical. It is supported by people with knowledge or training in modern medicine. Through scientific work (books, magazines, web graphics), the media (newspapers, television, radio), the respondents manage to get around it, since they are made aware of it. The second cause is metaphysical. It is linked to the sociocultural environment of the actors. The disease is perceived as the consequence of the deliberate act of a third person (invisible) on the individual, often presented as an evil spirit (sorcerer). The following table corroborates the above comment:
Table 2. Causes of High Blood Pressure.

\begin{tabular}{lll}
\hline Numbers Answers & Respondents & Pourcentage (\%) \\
\hline Physical causes & 16 & 16 \\
Metaphysical causes & 84 & 84 \\
Total & 100 & 100 \\
\hline
\end{tabular}

Source: Our survey, 2019.

Out of 100 respondents, 31 respondents around 31\% support physical causes. These are the causes identified by biomedicine, including poor diet, lack of sport, which influence the health of "Koyaka". This assumes that the individual is responsible for his illness. When $69 \%$ of individuals (the majority) indicate magico-religious causes. For this social category, the individual is subject to influence, even social pressure. It is therefore the social environment that is responsible for his illness. Different behaviors are detected.

\subsection{Behaviors of the Actors}

To identify the respondents' ways of acting, we asked them the following questions: "What products do you consume"? "What sport do you play"? "Do you use contraceptives"? Here are some of the responses:

"I eat almost everything. Meat from sheep, cattle, goats, poultry. I prefer when the sauce is spicy and salty. Often, in the company of friends, in restaurants, in the "maquis", I consume in the company of friends chicken or braised fish, well seasoned in the "Maggi cube". I like it when the food is accompanied by beer or wine. These good dishes give health. Besides, I am overweight. I don't know why I should do sports. I didn't want to tire my body" (P. N, 48, shopkeeper).

"I smoke cigarettes. Every day, I do not deprive myself of this passion. It comforts me, allows me to escape, or even forget about permanent worries. She's really my everyday companion. I also consume the alcoholic drink. Ice beer and wine, I love it especially in the maquis, where we order chicken, charcoal fish "(D. K, 40, hairdresser).

"To avoid unwanted pregnancies, sexually transmitted diseases, I use products (tablets, capsules). For years, I practice contraception. It also allows me to space births, because children's health depends on them. But also, because life is expensive today "(S. F, 50, Housewife).

Through these comments, we identified different behaviors among the respondents, which are linked to poor eating habits. These are the abuse of tobacco (addictions) and alcoholic beverages. It is also about the quality of the food consumed, often risky mixtures (cigarettes and alcoholic beverages, alcoholic beverages and chicken or charcoal fish, seasoning cube). To these eating behaviors are added the use of cosmetic products, the absence of sport, as many ways of doing things, emanating from the words of the actors, which exposes them to high blood pressure.

\subsection{Therapeutic Routes}

In order to analyze the respondents' reaction to the disease, we asked them the following question: "How do you treat 
high blood pressure"? Here are some of the responses:

"When my grandfather was sick, my uncle went out into the bush and picked plants. The harvested leaves are placed in a canary brought to the boil. The decoction obtained is used in the form of a steam bath. After cooling, the liquid obtained is administered by the oral route. It was when the disease persisted that he was evacuated to the hospital "(H. E, Student, 40 years old).

Since I got high blood pressure, I have had two types of treatment. I start with traditional care, that is to say the plants, the roots and the bark. But that does not prevent me either from going to a health center (hospital) to receive treatment. As my daughter is a caregiver, she always accompanies me on my appointments and advises me on taking medication. (V. K, Farmer, 72 years old)

Honestly, ever since my brother got sick, I have been going to the hospital for treatment. Advice on use is given to him, among other things, respect for diet, hygiene. This allows me myself to monitor my diet, and to practice sport regularly" (F. D, Secretary, 41 years old).

The remarks show that the means used to recover health depend on the perceptions of the people questioned. Each cause has a well-indicated social environment and treatment. Thus, the first which is physical rhymes with modern treatments. The second corresponding to the magicoreligious dimension is linked to traditional treatments. As a result, we are in the presence of two spaces: the local and the global. The above data are discussed.

\section{Discussion}

\subsection{Populations Facing High Blood Pressure}

This first axis indicates a small proportion of women with a good knowledge of high blood pressure. The socio-cultural environment, particularly the level of education explains this reality. Indeed, the respondents have human capital, or even experience, skills (knowledge, know-how, interpersonal skills) on high blood pressure, because of the training received during the school or university course. Situation of discomfort, it impacts, according to them, negatively the health of the populations. High blood pressure is an exaggerated increase in blood pressure. It presents itself as a debilitating disease, since it causes paralysis, strokes. It is noticeable through signs or symptoms such as (headache in the morning on the top or behind the head; dizziness, visual disturbances: flying flies, fog in front of the eyes; nosebleeds, conjunctival hemorrhages, muscle cramps. are physical in nature, such as poor diet, lack of rest and sports, stress, consequences of illness and poorly treated pathology, and may be linked to the consumption of 'alcohol, tobacco These words are justified by various works.

For Rossant [6], high blood pressure (hypertension) is the permanent rise in blood pressure figures (called blood pressure or BP) above $14 / 9$. Ideally, it is $12 / 8$. There are factors that promote high blood pressure. It is a diet too salty, alcoholism, smoking, oral contraceptives, emotional and repeated shock, obesity, lack of physical exercise. The development of high blood pressure causes neurological accidents (stroke), sensory accidents (ocular hemorrhage, paralysis of the oculomotor nerves, dizziness), cardiac accidents. Aside from these acute accidents, he argues, the increase in blood pressure over time affects the vessel wall, which is not expected to undergo such pressure regimes. Among the harmful effects is the acceleration of the atherosclerosis process. The organs that suffer most often are the central nervous system (risk of hemorrhage), the retina (retinopathy), the heart (left ventricular overload), the penis (erectile dysfunction). Different foods and products are also responsible for high blood pressure. We distinguish bananas, coconuts, vanilla, phenacetin, nonsteroidal anti-inflammatory drugs, ciclosporin, nasal vasoconstrictors used for chronic rhinitis or migraine.

Anserm [7] agrees. The author maintains that hypertension (hypertension) is the most common chronic disease in France. Linked to an abnormally high pressure of blood in the blood vessels, it seems harmless because it is generally silent. However, when it is not controlled, it is one of the main causes of cardiovascular, cerebrovascular or neurodegenerative complications (myocardial infarction, stroke, Alzeimer disease, etc.). Like other pathologies, physical factors explain the disease. These are genetic causes (Cooper [8]; Kaplan [9], socio-economic causes (Bertrand [10]; Kaufman [11]), lifestyle habits linked to urbanization (Kaufman [12]) For Bertrand [10], the increase in age is associated with the occurrence of high blood pressure.

In addition to the above-mentioned physical causes identified by the respondents, those are socio-cultural. They are linked to the influence of the social environment, even the experience or daily practices of the populations. We distinguish the action of invisible hands. In traditional Africa, death and disease are not accidental. In the cosmogony of populations, there is always an explanation for the events that occur. When it comes to high blood pressure, a man is the victim of assault by a third person. In many cases, the land, clothing, and real estate heritage that arouses lust justifies intervention or metaphysical action. Thus invisible beings, sorcerers for some, geniuses, fetishists, dead for others, not satisfied with the ways of acting of a member of the community (family, lineage) operate mystically, by casting a spell or disease ( high blood pressure).

This perception is deconstructed among certain peoples, particularly the odjukru of the lower Côte d'Ivoire. For them, man is responsible for his illness. Indeed, it is because the individual went to seek it; it is because he caused her that the disease follows him, that she becomes his everyday companion. Thus, the man takes full responsibility for his actions, which is translated by the expressions: ôl ba otch a (you got the results of your action) or b'ôl k'otch (who seeks finds), supports Akmel [13].

The prophet Atcho Albert de Brebgo also broke with the traditional interpretation of the disease, grounding the origin of the evils in a persecutory power, exercised by another individual. This is why, he proposes a new conception of the 
person and of disease. The sick subject is not the object of persecution by another, he is himself responsible for his illness. In this case, no healing process can be envisaged without the patient's confession. By confession, the individual becomes aware of his faults. Disease sent by God to punish the evil accomplished, confession allows the forgiveness of God and the recovery of health, says Piault [14]. The Bible testifies: "If you find honey, eat only what you need, for fear that you will be full and that you will vomit it up," says Segond [15]. It is less the consumption of honey than its abuse, which leads to rejection. He exceeded the standards of his organism, as a result, he vomited; a situation similar to that of the frog, which wanted to make itself as big as the ox, in spite of its smallness, and which ended up bursting.

\subsection{Risky Practices}

It's about eating habits. Indeed, many of the respondents, who abuse tobacco (addiction), chewed or smoked, often accompanied by alcoholic beverages, which exposes them to heart problems, hypertension. The impact of these products on health is supported by a number of researchers. According to Madika [16], nicotine can temporarily raise blood pressure (BP) by an immediate effect on the sympathetic nervous system. Smoking accelerates the arterial stiffness processes involved in chronic vascular hypertension. Chronic smoking also induces sympathetic activation which in the long term interferes with lipid metabolism and insulin resistance. It can contribute to the development of atheromatous renal arterial stenoses, aggravating causes of hypertension. Often, it is associated with higher consumption of alcohol; all this contributes to a poor blood pressure balance in very high risk patients.

This is the justification for Corvol's thesis [17]. For the author, the actors in the fight against smoking argue, so that knowing the risk imposes the responsibility (and therefore the guilt) of the manufacturers. In fact, identifying the risk associated with smoking is not a simple problem. If today, the epidemiological evidence of the harmful effects of tobacco is solid, it was not the case yesterday. Doctors were unable (or unable) to immediately recognize tobacco as a cause of lung cancer and arterial disease. The medical awareness of the harmful effects of tobacco was progressive. This is what lawyers for victims of tobacco addiction claim, which the tobacco industry defends.

What about food? Can you eat safely, especially in underdeveloped countries? It would be a myth. In Europe where technology is advanced and safety measures developed, food is involved in the appearance of diseases such as obesity. Like rich countries, Africa is not spared. The poor diet of populations, linked to poverty and illiteracy causes many diseases, including high blood pressure. Indeed, the regular consumption of grills associated with alcoholic beverages (wine, beer, liqueur), excessively fatty foods, the consumption of foods rich in salt (cubic broths, spice mixture, mustard, cheese, classic bread, foods smoked, cold meats...) without moderation, expose populations to high blood pressure. The impact of the ways of thinking and thinking linked to the diet of Banco women on high blood pressure is justified by authors. According to the WHO [18], 91 million people fall ill, 137,000 people die from it, which represents $1 / 3$ of the global mortality due to food-borne illnesses. Diarrheal diseases are responsible for $70 \%$ of the burden of foodborne illness. Chemical risks (cyanide) cause $1 / 4$ of deaths. The paralysis caused by cyanide in cassava is specific to the African region and causes death (1 in 5 affected people).

This is also the position of Akmel [19]. The author claims that roasted fish and meat expose consumers to disease. Indeed in Togo, it is coconut shavings, sawdust, straws and recycled cardboard, which are used for smoking fish, which is consumed by the population, says Abotchi [20]. But fish smokers and restaurateurs use often toxic wood. We distinguish Acacia, teak, bete wood, tali, fraké, framire, kolatier, hevea. Authors have shown that these plant species are harmful to human health. Aké-Assi and Pity confirm the toxicity of green rubber and bete wood. These are chemicals found in rubber and mansoin for bete wood, which expose roasters and consumers to disease. Bete wood contains a dangerous poison that the people used to poison their arrows. The same is true of Tali, an essence that is mainly found in Côte d'Ivoire, Cameroon, Congo-Brazzaville and Gabon. Its bark provides a deadly poison. It should be remembered that the most harmful foods are those that are directly smoked and braised (smoked fish and various chickens and so-called "stuck" fish) with green cut rubberwood, maintains Fatime [21]. If social perceptions and behaviors expose actors to high blood pressure, they adopt strategies to cope with the disease.

\subsection{Medical Practices}

This axis focuses on respondents' responses when their state of physical, mental and social well-being (health) is threatened. Two reactions are offered to stakeholders, including the use of traditional treatments. The first reflex of women targets the local. It is about the cultural environment. Therefore, they use medicinal plants (bark, leaves, fruits, roots...) to recover health. The drugs collected are administered by oral, nasal, ocular, anal route. High blood pressure being perceived as, the action of an invisible hand by some respondents, traditional therapists are called upon. Abdoul [1] confirms that 55,000 patients are treated per year in sub-Saharan Africa. Women therefore turn to magicalreligious Africa to find solutions to their problems. According to Moustapha [22], it is about the Africa of the man, who sits on a stool, scans the horizon. He asks physical and metaphysical nature for support, through medicinal plants, the summoning of ancestors to recover healing.

When the disease persists, the respondents use the health centers. It is the modern Africa of democratic and republican institutions. It is about the Africa of the man, a briefcase in his hand, his gaze fixed on the west. He reaches out to Europe to find solutions to his health. Medicines (capsules, tablets, etc.) and chemical products are prescribed for the 
sick to cure them. This is the position of Vidal [23], who maintains that the treatments are based on lifestyle and dietary measures. If they are not insufficient to lower the blood pressure, a drug treatment is put in place. It can use several families of drugs, including diuretics, beta-blockers, calcium channel blockers, ACE inhibitors, and angiotensin II antagonists. These drugs have been shown to be effective in preventing cardiovascular events in people with hypertension. What to learn from this study?

\section{Conclusion}

The social perceptions, behaviors and therapeutic routes linked to high blood pressure among the Koyaka of Banco show that the notions of health and disease are not in exile in Africa. Faced with situations of discomfort, each society has used the spirit of creativity, the spirit of invention to provide solutions. Therefore, the fight against diseases should not focus only on the biomedical dimension which is material, western vision (examinations, administration of drugs, lifestyle...). On the contrary, it must be multidimensional, taking into account the socio-cultural environment or the daily experience (ways of doing, thinking, feeling) of populations, African vision. In other words, the involvement of medical anthropology in understanding, explaining and combating hypertension (a public health problem) finds its justification.

\section{Acknowledgements}

We would like to thank, very sincerely the organizing committee of the World Journal of Public Health for this Special Issue, which they were kind enough to devote to us. Our infinite gratitude goes to the Koyaka women from Banco to Bouake and to the many informants, who made this research possible.

Nous tenons à remercier, très sincèrement le comité d'organisation de la Revue Mondiale de Santé Publique (Word Journal of Public Health) pour ce numéro spécial, qu'il a bien voulu nous consacrer. Notre infinie gratitude va aux femmes Koyaka de Banco à Bouaké et aux nombreux informateurs, qui ont rendu possible la réalisation de cette recherche.

\section{References}

[1] K. Abdoul (2017). High blood pressure in sub-Saharan Africa: the challenges, 37th day of high blood pressure. Paris, 38p.

[2] F. Jarraya, K. Kammoun (2012). Management of high blood pressure in Tunisia: the challenge of a developing country. Perspective, 8, 1725-1730.

[3] D. Boukare (2014). High blood pressure in the adult population of Burkina Faso: Prevalence, detection, treatment and control. Montreal, 262p.

[4] V. Aline (2010). Social representations. Louvain-la-Neuve, 169-170.

[5] P. F. Noppen (2012). The subject of dialectics. Archives of Philosophy, 3 (75), 449-470.

[6] J. L. Rossant, L. Rossant (2017). High blood pressure: symptoms to treatment. Doctissimo, 21p.

[7] INSERM (2018). Science for health: High blood pressure. Science for health, 13p.

[8] R. Cooper, C. Rotimi (1994). High blood pressure in populations of West Africa origin: Is there a genetic predisposition? J. Hypertens, 12, 215-227.

[9] N. M. Kaplan (1994). Ethnic aspect of the high blood pressure. Lancet, 344 (8920), 450-452.

[10] E. Bertrand, O. Akinkugbe (1995). High blood pressure in populations originating in Black Africa. Paris, $64 \mathrm{p}$.

[11] J. S. Kauffman, N. Barkey (1993). Hypertension in Africa: an over-view of prevalence rates and causal risk factors. Ethnic Dis, 3, 83-101.

[12] J. S. Kaufman, E. Owoaje (1996). The determinants of hypertension in West Africa: contribution of anthropometric and dietary factors to urban-rural and socio-economic gradients. Epidemiol, 143, 1203-1218.

[13] M. S. Akmel (2005). Socio-sanitary impact of the exploitation of cassava, "Manihot esculenta Crantz" on peasant populations in Odjukru country, Bouake, 390p.

[14] C. Piault (1975). Prophetism and therapy. Atcho Albert and the community of Bregbo, Paris, 150p.

[15] L. Segond (1979). The Holy Bible, Geneva, 2302p.

[16] A. L. Madika, C. M. Vahier (2017). Tobacco, High blood pressure and regulation of blood pressure. Lille, $3 p$.

[17] P. Corvol, V. P. Nicolas (2010). Cardiovascular risks of smoking: late recognition of an uncontrolled epidemic. The letter from the Collège of France, 3, 40-49.

[18] O. M. S (2015). Foodborne illness in the WHO African region. WHO Africa, $1 \mathrm{p}$.

[19] M. S. Akmel, A. S. Agnero (2017). Socioeconomic impact and health constraints of roasting meat in Bouake (Ivory Coast). Ivory Letters, 2 (026), 233-244.

[20] K. Abotchi (2010). Evaluation of the microbiological quality of artisanally smoked fish in Togo, Dakar, 30p.

[21] S. Fatime (2013). Braised fish, braised chicken, choukouya... Be careful, smoking charcoal kills. LG, 10p.

[22] D. Moustapha (1999). Capacitance Indicametry. Bouake, 22p.

[23] VIDAL (2018). High blood pressure medications. EurekaSanté, $17 \mathrm{p}$. 